Dr Dragan M. Stojanović

profesor Pravnog fakulteta u Nišu

\title{
O USTAVNOSTI ODREDABA ČLANA 88. STAV 1. TAČ. 1. I 9. ZAKONA O IZBORU NARODNIH POSLANIKA*
}

Osporene odredbe Izbornog zakona Srbije na osnovu kojih mandat narodnog poslanika prestaje gubitkom članstva u političkoj partiji ili koaliciji stranaka, odn. brisanjem stranke iz registra političkih partija, nisu u skladu sa Ustavom Republike Srbije, jer su suprotne načelu slobodnog poslaničkog mandata i principu zabrane rotacije članova predstavničkog tela. Imperativni poslanički mandat je, bilo izričito bilo implicite, zabranjen u modernim predstavničkim sistemima, kao i rotacija članova parlamenta, osim u onim slučajevima kada je ona logična posledica objektivne nemogućnosti daljeg vršenja pojedinačnog predstavničkog mandata.

\section{II}

Nema sumnje da su u modernim demokratijama gde političke partije dominiraju i gospodare državnim životom dalekosežno promenjene struktura i funkcije parlamenta. Narodno predstavništvo je svuda u znatnoj meri izgubilo od svoje izvorne suštine koja mu je davala karakter centralnog organa političkog odlučivanja. Mada najvišoj političkoj reprezentaciji naroda formalno i dalje pripada ključna uloga u procesu obrazovanja državne volje, ne može se prevideti da je delovanje parlamenta suštinski determinisano odlukama i odnosima političkih partija. Teško se, dakle, može pobijati tvrdnja da je u demokratiji ,države partija” parlament samo mesto gde se susreću vezani partijski nalozi i usvajaju formalne odluke koje su uglavnom negde drugde donete.

* Rad primljen: 27. II 2003. 
S druge strane, bez obzira na izmenjenu ulogu narodnog predstavništva, čija je pozicija prema egzekutivi upadljivo oslabljena, nesporno je da parlament, bar formalno, ostaje centralna politička institucija ustavnog sistema i političkog odlučivanja. Dobrim delom, njegova politička uloga, naročito u procesu stvaranja prava, određena je akcionim mogućnostima koje parlamentarno pravo priznaje njegovim članovima, tj. poslanicima. Međutim, te mogućnosti poslanika se samo delimično pokazuju kao pravno odredive, i to samo onda kada se mogu neposredno vezati za ustavno načelo slobodnog poslaničkog mandata. Najvećim delom, akcione mogućnosti poslanika su determinisane osnovnim političkim odnosom u kojem se poslanik nalazi. U političkom pogledu, dakle, član parlamenta je potčinjen političkoj partiji koja je njemu omogućila sticanje poslaničkog mandata, tj. članstva u parlamentu, tako da se poslanik faktički pre pokazuje kao njen politički reprezentant, nego kao nezavisni predstavnik nacije.

Poslanički mandat je takva javna funkcija na koju se dolazi putem izbora koji se ne mogu zamisliti bez političkih partija. Izbori se, dakle, pre pokazuju kao biranje političke partije, nego kao izbor ličnosti. Nije daleko od istine mišljenje G. Leiholz-a da izbori u suštini imaju funkciju registrovanja i statistike, jer imaju zadatak da pokažu numeričku vrednost određenih političkih pravaca u narodu. Oni primoravaju i građane koji nisu partijski organizovani da se izjašnjavaju u korist programske i personalne ponude jedne od političkih partija. Prema tome, mandat se u suštini dobija od političke partije, ali nije bez uticaja način njegovog dobijanja. Kod uninominalnih izbora, kada se u izbornoj jedinici bira samo jedan poslanik, kandidat koji je pobedio može da se poziva na lično stečeno poverenje birača, mada je jasno da bez pomoći partijskog aparata njegova pobeda ne bi bila moguća. Birači se u ovom izbornom modelu opredeljuju i za političku partiju i za kandidata. Kod proporcionalnih izbora birači glasaju za političku partiju i personalni sastav kandidatskih listi gotovo da je bez ikakvog uticaja. Stoga je i faktički položaj poslanika ovde još slabiji. Ovaj očigledan nedostatak proporcionalnih izbora pokušava da se ublaži na različite načine. Tako se biračima u nekim izbornim sistemima daje mogućnost da ako već ne mogu da utiču na sastav izborne liste odrede bar redosled kandidata na njoj. U tom slučaju može se govoriti o nekoj vrsti personalizovanih proporcionalnih izbora.

\section{III}

Iz izloženog proizlazi da karakter savremenih izbora dalekosežno utiče na političku, delimično i na pravnu poziciju poslanika. Ako izbore više niko ne vidi kao biranje najboljih pojedinaca, nego kao utvrđivanje snage političkih partija, onda se ne može izbeći da ,poslanik načelno bude potčinjen stranoj volji” (F. Koja). Pošto se de facto mandat dobija od političke partije, onda i poslanik nije više reprezentant naroda koji slobodno, potčinjen samo svojoj savesti, učestvuje u donošenju političkih 
odluka. Izabran sa partijske liste u proporcionalnom ili podržan od partije u većinskom izbornom sistemu, poslanik je ,dužan" da u parlamentu deluje onako kako je to partija obećala biračima u svom načelnom i izbornom programu. Partijska lojalnost poslanika reflektuje se, uostalom, i kao fer plej prema biračima. Jednostavno, što je više izbor poslanika zavisan od partije, a ne od posebnih političkih kvaliteta i ličnih osobina, to više slabe i akcione mogućnosti poslanika u parlamentu. Tačnije, one su dirigovane od političke partije i parlamentarne, odn. poslaničke grupe kojoj poslanik pripada.

Prema tome, promenjeni karakter izbora doveo je do strukturalnih promena u samom parlamentu i konačno do njegove funkcionalne zavisnosti od parlamentarnih grupa, odn. političkih partija. Legitimacioni lanac sada se pokazuje na sledeći način: birači-partija-poslanici-poslanička grupa-parlament. U ovom lancu presudna karika je politička partija, dok su uloge ostalih karika u njemu bitno redukovane. Ako se, međutim, može prihvatiti da je uticaj partija neizbežan, nameće se pitanje do koje mere je on ustavnopravno dozvoljen, naročito prema poslaničkoj grupi i poslaniku pojedincu. Ključno pitanje je, dakle, kakav je sadržaj i gde su granice pravno dozvoljene partijske ili frakcijske prinude prema poslaniku? Ako vezanost poslanika za političku partiju ide sve do gubitka mandata, onda ustavom proklamovano načelo slobodnog poslaničkog mandata gubi svaki smisao.

\section{IV}

Načelo slobodnog mandata isključuje mogućnost da se prema poslaniku preduzimaju mere pravnog karaktera u slučaju da se on ne pokaže lojalnim prema svojoj poslaničkoj grupi, odn. političkoj partiji. Kao što ne postoji pravna, nego samo politička veza između poslanika i birača, tako i ne postoji nikakva vezanost poslanika za partiju koja ga je prezentovala ili za poslaničku grupu kojoj pripada u parlamentu. Prema tome, sve mere partijske ili frakcijske prinude imaju samo interni karakter i ne bi smele da ugroze ustavnopravni položaj poslanika. No, bez obzira što nemaju pravni karakter, sankcije za povredu frakcijske discipline itekako deluju na ponašanje poslanika. Nekada su i sama pretnja ili nagoveštaj da poslanik neće biti kandidat na partijskoj listi, odn. da neće biti ponovo nominovan, dovoljni da iznude ,poslušnost” poslanika. Poslanička funkcija je dovoljno prestižna i unosna da kod većine poslanika motiviše želju za njenim što dužim vršenjem. Zato ne deluje ekstremno što u nizu država parlamentarci sede po više decenija u poslaničkim klupama. Druge mere koje partija može da preduzme prema poslaniku su, ipak, daleko radikalnije. Prva konkretna mera prema poslaniku koji krši frakcijsku disciplinu je njegovo povlačenje iz parlamentarnih odbora. Ako se ona pokaže neuspešnom, onda slede isključenje poslanika iz poslaničkog kluba i političke partije. 
Poslanik kome je prestalo članstvo u političkoj partiji ima moralnu i političku obavezu da vrati mandat. Ali, pravna obaveza na vraćanje mandata ne postoji, jer bi protivurečila Ustavom priznatom načelu slobodnog mandata. Iako su izabrani sa partijskih listi, poslanici su u vršenju svoje funkcije reprezentanti čitavog naroda, a ne njegovog parcijalnog dela. I odredba člana 76. Ustava Srbije po kojoj narodni poslanik predstavlja građane izborne jedinice u kojoj je izabran ne znači da poslanik nije i predstavnik nacije u celini, niti da se država obavezno mora deliti na više izbornih jedinica. Ako bi poslanik predstavljao samo građane izborne jedinice u kojoj je izabran, onda bi bilo logično da ga birači mogu opozvati, odn. ako se država mora deliti na veći broj izbornih jedinica, onda bi sadašnji sastav Narodne skupštine trebalo smatrati protivustavno izabranim.

Slobodan mandat isključuje bilo kakve obavezujuće naloge birača poslaniku, čije nepoštovanje bi dovodilo do njegovog opoziva. Tome bi protivurečilo i kada bi se opoziv poslanika predao partijskim instancama, tim pre što one mogu da isključe poslanika iz parlamentarnog kluba i iz razloga koji ne stoje ni u kakvoj vezi sa njegovom poslaničkom funkcijom. Pored toga, ekskluzivno pravo političkih partija na opoziv poslanika obesmislilo bi parlamentarne izbore i njihovu demokratsku suštinu. Ako bi partije bile ,suverene" u izboru i opozivu poslanika, onda bi izbori bili zapravo nepotrebni. Dovoljno je da političke partije dokažu svoju jačinu i da shodno tome same izaberu svoje poslanike. Prirodno, to bi značilo da ih one mogu menjati po svom nahođenju. U tom slučaju, parlament više ne bi imao karakter državnog organa, nego bi bio uslovno sveden na svojevrsni međupartijski odbor.

Treba uvek imati u vidu da se upravo načelom slobodnog mandata predupređuju krajnje konsekvence koje bi proizišle iz radikalno izvedene demokratije „države partija”. Ovo ustavno načelo bi, dakle, trebalo da eliminiše krajnosti, zloupotrebe partijske države i potpunu potčinjenost poslanika parlamentarnoj grupi i političkoj partiji. Prema tome, između poslaničke grupe i političke partije, na jednoj strani, i poslanika na drugoj, može da postoji samo politički, ne i pravni odnos. Ako poslanik ne oseća moralnu obavezu i odupre se političkom pritisku da vrati mandat, onda je to interno partijsko pitanje u koje država ne bi trebalo da se meša. Zaštita partijske ili frakcijske discipline nije u kontekstu njenih zadataka. Prema tome, država ne sme da dónosi mere kojima bi se učvršćivala stranačka disciplina, ali ni mere koje bi poslanika štitile od internih partijskih sankcija.

Izborni zakon Srbije je verovatno jedan od retkih zakona u Evropi, moguće je čak i jedini, koji predviđa prestanak poslaničkog mandata zbog prestanka članstva u političkoj partiji, odn. koaliciji na čijoj listi je posla- 
nik bio izabran. Njega nema u parlamentarnom pravu Francuske i Engleske, gde su izbori uninominalni, niti u Austriji, gde su izbori proporcionalni, ali ni u Nemačkoj gde se polovina članova Bundestaga bira prema uninominalnom, a polovina prema proporcionalnom izbornom modelu. Mišljenje da je ovaj osnov prestanka mandata neustavan izložili smo još u vreme važenja ranijeg izbornog zakonodavstva SR Jugoslavije i Srbije od 1992. po kojem mandat poslanika prestaje istupanjem iz političke partije na čijoj listi je poslanik bio kandidovan. Izmenama izbornog zakona od 1997. u Srbiji uveden je i formalno ,partijski opoziv” poslanika. Dok se ranije mandat gubio samo kada je poslanik svojom voljom napuštao partiju, sada više nije bitan način na koji je prestalo njegovo članstvo u političkoj partiji sa čije liste je on dobio mandat. Zanimljivo je da u vreme uvođenja ovog spornog osnova za prestanak poslaničkog mandata nijedna značajnija politička stranka nije osporavala njegovu ustavnost.

Prema mišljenju nekih konstitucionalista ovaj osnov prestanka poslaničkog mandata samo je logična posledica primene načela srazmernog predstavništva kod raspodele poslaničkih mandata. Tako, na primer, R. Marković navodi da ,ako prestane veza predstavnika i političke stranke posredstvom čije izborne liste je predstavnik dobio predstavnički mandat na parlamentarnim izborima, kao i ukoliko za vreme tog trajanja mandata politička partija prestane da postoji, time prestaje da postoji i mandat narodnom poslaniku" (Ustavno pravo i političke institucije, 1995, str. 301). Proizilazi, dakle, da se prestankom jednog političkog odnosa, tj. političke veze gubi ustavnopravni status poslanika. Međutim, konstatacija da je prestanak mandata zbog gubitka članstva u političkoj partiji posledica proporcionalnih izbora ne stoji. Tačno je samo da je kod ovih izbora, za razliku od personalizovanih izbora, politička zavisnost poslanika od političke partije očiglednija, ali ona uvek ostaje samo politička, a ne i pravna zavisnost. Logika je svake reprezentacije, pa i srazmerne, da je mandat reprezentanta u pravnom pogledu slobodan, bez obzira na njegovu mnogostruku faktičku zavisnost, pre svega, od političke ili izborne partije. Ukoliko bi veza između poslanika i političke partije dobila pravni karakter, onda bi u suštinskom smislu bila razorena ideja reprezentacije $\mathrm{i}$ izbora uopšte. $\mathrm{Na}$ ovaj način, tj. davanjem partiji mogućnosti da poslaniku oduzme mandat, zapravo se uvode imperativni mandat, opoziv i princip rotacije članova predstavničkog tela. Doduše, rotacija, odn. zamena jednog poslanika drugim, prema nahođenju političke partije, ograničena je samo na lica koja su se nalazila na partijskoj izbornoj listi, ali se time suština stvari ne menja.

Ono što važi za prestanak mandata dobijenih sa stranačke liste trebalo bi da važi i za mandate dobijene sa koalicionih izbornih listi. Ako stranka ne može da bude ,vlasnik" mandata, onda to ne može da bude ni koalicija stranaka. Zabrana imperativnog mandata i rotacije članova parlamenta važi ne samo za stranku, nego i za stranačke saveze. Prema tome, raskidanje, napuštanje ili isključenje iz koalicije ne bi moglo da vodi prestanku već dobijenih poslaničkih mandata. Niti koalicija može „oduzeti 
mandate" poslanicima stranke koja je napustila koaliciju ili je iz nje ,izbačena”, niti ova stranka može ,promeniti” poslanike koji su ostali lojalni koaliciji. Prema tome, načelo slobodnog poslaničkog mandata mora da bude održano i u ovom slučaju. Zakonito dobijeni poslanički mandati mogu prestati samo iz onih razloga koji nisu suprotni ovom načelu. Prema tome, politička pregrupisavanja u parlamentu ne mogu da se vrše bez poštovanja slobodnog poslaničkog mandata. Poslanik je, dakle, slobodan da napusti jedan poslanički klub i pređe u drugi, odn. da sa drugim istomišljenicima formira novu poslaničku grupu. Naravno, to znači da će u svakoj narednoj izbornoj utakmici političke stranke biti primorane da strogo vode računa o tome koja lica nominuju, odn. da li će i sa kojim strankama sklapati predizborne koalicije. Uostalom, političke posledice slobodnog mandata, koje su u drugim zemljama prilično jasne, u našem parlamentarnom životu mogu da budu potpuno drugačije. Dosledno poštovanje slobodnog mandata može se pokazati kao daleko lakši način da se očuva parlamentarna većina, nego što je to slučaj sa partijskom rotacijom poslanika.

Ni statusne i organizacione promene koje mogu nastupiti kod političkih stranaka ne mogu biti od uticaja na sudbinu mandata. Prema tome, mandat poslaniku ne može prestati brisanjem stranke iz registra političkih partija, promenom naziva stranke, podelom stranke i sl. Egzistencija predstavničkog mandata ne može se vezivati za političku partiju, jer se mandat, bar formalno, dobija od birača. Bez obzira da li se radi o uninominalnim ili proporcionalnim izborima, kandidati koje su nominovale političke ili izborne partije, koje se kod nas nazivaju grupe građana, verifikuju jedino birači. Ako je volja birača u pravnom pogledu bez uticaja na vršenje mandata, onda se ni njegova sudbina ne može dovoditi u neposrednu vezu sa sudbinom onoga ko je formalno predložio kandidata za poslanika. Uostalom, ni ovaj osnov prestanka mandata se ne predviđa u parlamentarnom pravu drugih država. Jedini izuzetak je prestanak mandata zbog zabrane delovanja političke partije koji je predviđen, na primer, u Nemačkoj, bez obzira da li je mandat stečen uninominalnim izborom ili je dobijen sa partijske liste. Samo u ovom slučaju je veza poslanika i zabranjene političke partije pravna veza. Logično je da konstatacija Ustavnog suda da je politička partija ,zločinačko udruženje” mora da vodi gubljenju poslaničkih mandata njenih članova.

\section{VI}

Nesporno je da utvrđivanje osnova za prestanak mandata poslanika ulazi u domen autonomije parlamenta, ali je takođe nesporno da je svuda ova autonomija ograničena ustavnim načelom slobode mandata. Štaviše, neki ustavi, na primer, francuski Ustav od 1958, nalaze da je neophodno da se i izričito proglasi ništavost svakog imperativnog mandata. U svakom slučaju, ukoliko Ustavni sud Srbije utvrdi da je i prema Ustavu Re- 
publike Srbije mandat poslanika slobodan, odn. da je njime isključen bilo kakav oblik imperativnog mandata, onda bi Sud morao da deklariše neustavnim osporene odredbe Zakona o izboru narodnih poslanika.

Po mom sudu, ni time se, međutim, ne bi u potpunosti obezbedila ustavna garancija slobodnog mandata. Imajući u vidu da je tzv. blanko ostavka takođe nedozvoljeni oblik partijskog pritiska na slobodno vršenje i zadržavanje poslaničkog mandata, dakle, da je ona suprotna slobodnom mandatu, celishodno bi bilo da Ustavni sud u obrazloženju svoje odluke konstatuje takođe da je ništavna svaka unapred potpisana ostavka poslanika.

Prema tome, čak i kada bi se deklarisale neustavnim odredbe Zakona o prestanku poslaničkog mandata zbog prestanka članstva u političkoj partiji, odn. koaliciji stranaka, u našem parlamentarnom pravu bi preostao jedan indirektan način ,partijskog opoziva” poslanika, tj. aktiviranje tzv. blanko ostavke. Uostalom, one su u našem parlamentarnom životu bile veoma aktuelne sve do uvođenja ekskluzivnog prava političkih stranaka na zakonito oduzimanje mandata koje se sada osporava. Da bi se, dakle, potpuno potvrdila stabilnost ustavnopravnog položaja poslanika neophodno je da Ustavni sud zauzme stav kojim se potvrđuje da je demokratska legitimacija poslanika samostalna, bez obzira što su narodni poslanici dobili mandat na osnovu toga što su ih političke ili izborne partije prihvatile za svoje kandidate. Potvrda samostalnosti njihove demokratske legitimacije značila bi da isključivanje iz partije ili poslaničkog kluba ili prelaz iz jedne partije u drugu ne može da vodi gubitku mandata. Ukoliko poslanik dođe u takvu situaciju, onda on može da bude uskraćen jedino za ona prava koja se izvode iz pripadnosti poslaničkoj grupi, kao samostalno demokratski legitimisanoj reprezentaciji u parlamentu. Prema tome, obaveze poslanika da će u takvom slučaju, tj. napuštanju ili isključenju iz partije vratiti mandat, kao i unapred date pisane izjave o ostavci, Ustavni sud bi morao da deklariše pravno ništavim. 